\title{
Understanding issues of people living with disabilities in South Africa
}

A Sathiya Susuman, Renette Blignaut and Siaka Lougue

\begin{abstract}
The problem of disabilities is growing all over the world. Nevertheless, some progress has been made since the year 1981 was proclaimed International Year of Disabled Persons. In 2001 people living with disabilities accounted for 5\% of the South African population. Because of their disabilities or the perception society has regarding their potential, this population is mostly economically inactive. This study assesses the relationship between disabilities and the adverse socioeconomic impacts. Both descriptive and logistics regression models are used to understand the problem by exploring the data of the 2006 South African General Household Survey. The overall people living with disabilities and aged 15-49 years is estimated at 1742 (961 males and 780 females), when exploring people with disabilities findings reveal that the Western Cape Province's disabled are mostly affected by physical disabilities (40\%). People living with disabilities are 3.5 times $(p<0.01)$ more likely to suffer from illness/injuries (flu, tuberculosis (TB) and severe cough, diarrhea, blood pressure and HIV/AIDS) than others. Therefore, the study aims to contribute to a better condition of people living with disabilities in South Africa by informing and possibly changing the public perception about them.
\end{abstract}

\section{Introduction}

The problem of disabilities is growing all over the world. Nevertheless, some progress has been made since 1981 was proclaimed International Year of Disabled Persons. In the domain of human rights related to disability issues, a reform process is under way throughout the world. But that process is slow and uneven, and in some places almost non-existent (Quinn and Degener, 2003). At the international level, the World Health Organization (WHO) plays a key role in preventing injuries and violence, mitigating their consequences and enhancing quality of life for persons with disabilities (World Health Organization, 1980; 1985). However, Cambosis et al. (1999) report that, while there are significant reductions in severe disabilities in Germany, France and Japan, there is no change in Australia, Canada, the Netherlands, Sweden and the United Kingdom (WHO, 1985; 2001). Another study in Britain (Murray, 2007) considered disabilities surveys from the late 1980 s to the late 1990 s and found an increasing prevalence of disabilities. These different studies differ in many aspects such as definitions used, data set used, time period, geographical areas, and so on (Mehta, 1983). 
In South Africa, the national statistics office (Statistics South Africa) provided the number of 2,255,982 people living with disabilities in 2001 representing $5 \%$ of the entire population of the country. Unfortunately, several prejudices about people living with disabilities, such as being considered as invalid or sick, affect them throughout their life. Traditionally, people living with disabilities are seen as people who are impaired, functionally limited and unable to do anything (Ahlburg et al., 1999). Attitudes against disabilities are deeply rooted in the social and cultural values of society (Banister and Zhang, 2005). Given this complexity of the situation, the lack of agreement on optimal measures about disabilities is not surprising (World Health Report, 2002).

According to the World Health Organization Report (2002: 1-2), 'a large proportion of people surviving their injuries incur temporary or permanent disabilities.' In South Africa, non-communicable diseases and disorders related to way of life such as diabetes, arthritis, stroke, cancer and so on are rapidly becoming important causes of disabilities. Poverty also increases the risk of disabilities, through vitamin A and iodine deficiencies, poor nutrition, bad working conditions, poor sanitation, environmental pollution and lack of health care (Sen and Wolfensohn, 2003). That is why the question of disability is such an important question of health.

Researchers from diverse professions like demographers, social scientists, medical scientists, human rights officials and so on are evincing keen interest in the subject of disabilities (Desai, 1990). According to Pathmanathan and Dhairiam (1990), demographers or social scientists almost exclusively reported measures of disabilities and trends in functional health. Measuring functional limitations and disabilities reduction among the working age population are important institutional and individual issues on many countries' scientific and policy agendas (Kapteyan 2004). Unfortunately, there is almost no study which has investigated disabilities particularly in the age group of 15-49 years. Several research articles focused on disabilities but none of them has been done in this specific age group and their socio-economic and demographic problems in South Africa. Therefore, we intend to examine this linkage using large-scale survey data.

\section{Aim of the Study}

The aim of this article is to understand disabilities among people of the 15-49 age group in South Africa. Disabilities are important health issues that emerged 20 years ago and discussions are needed on their risk factors and awareness on their causes and consequences. The problem can be analyzed in different ways, but in this study we focus on the dependent variable of suffering from disabilities. This study tried to assess and explain the causal link between disabilities and disable people's background characteristics. First, the trends of disabilities were examined and then the question of factors influencing disabilities. The present study correlates with understanding disabilities in South Africa.

\section{Hypothesis}


This study lies on the hypothesis of mutual influence between illness/injuries and disabilities. First, is the question of the vulnerability of people living with disabilities regarding illness/injuries. The lack of appropriate environments of work or living and the disability situation itself expose them to illness/injuries. In other words, people living with disabilities are more at risk of illnesses/injuries than the others. This study also suggests that illnesses/injuries are at the same times causes and consequences of disabilities. Thus the second hypothesis is related to illnesses/ injuries as causes of disabilities and states that illness/injuries are the main reasons for disabilities among the population. The consideration of other background variables in the model aims to highlight the role of socio-economic factors in the process of influence of illness/injuries on disabilities.

\section{Method}

The South Africa General Households Survey (GHS) 2006 is the data source used in this article. The GHS is a statistical survey conducted in South Africa with three major data sets: household, persons and workers files. The survey covered the nine provinces of the country: Western Cape (WC), Eastern Cape (EC), Northern Cape (NC), Free State (FS), Kwazulu Natal (KN), North West (NW), Gauteng (Gau), Mpumalanga (Mpu) and Limpopo (Lim). The present study mainly focused on respondents in the age group 15-49 years corresponding to a total of 55,384 people composed of 25,859 males and 29,525 females. Among this population, 5,935 suffer from illness/injury (2,469 males and 3,466 females). The overall people living with disabilities and aged 15-49 years is estimated at 1,742, with 961 males and 780 females. This article provides estimates of disabilities by province in association with background characteristics of the target population. The analyses were both descriptive and multivariate in a form of logistic regression. The study describes the relationship between suffered disabilities and each independent variable. Based on the bivariate analysis, logistic regression models were built. The models were based on weighted cases with disabilities as dependent variables and selected socio-economic and demographic variables as main independent variables.

\section{What is Disability?}

'Disability is the disadvantage or restriction of activity caused by a society that takes little or no account of people who have impairments and thus excludes them from mainstream activity' (British Council of Organizations of Disabled People, 1987: 70-71).

\section{Variables Used}

The socio-economic environment of people living with disabilities influences their living condition. In addition to age, sex, provinces, variables related to marital status, literacy (ability to read and write), family support (spouse alive, mother and father alive) and illness/injuries (flu or sexually transmitted infection [STI], diarrhea, TB and severe cough, blood pressure and HIV/AIDS) are important risk factors of disabilities. In order to strengthen knowledge about the issue, the influence of selected socio-demographic variables on disabilities is also analyzed.

\section{https://repository.uwc.ac.za}


Table 1. Total number of disabilities and their percentage distribution by province in South Africa (GHS, 2006).

\begin{tabular}{|c|c|c|c|c|c|c|c|c|c|c|}
\hline & & Male & Female & Sight & Hearing & Communicatin & Physica & Intellectua & Emotiona & Other \\
\hline WC & 213 & 113 & 100 & 7 & 7 & 2.8 & 40 & 18.3 & 8.9 & 16 \\
\hline $\mathrm{EC}$ & 284 & 171 & 113 & 14.8 & 10.9 & 8.1 & 32.7 & 27.5 & 6 & o \\
\hline $\mathrm{NC}$ & 136 & 77 & 59 & 20.6 & 12.5 & 9.6 & 32.4 & 22.1 & 7.4 & 5.1 \\
\hline FS & 129 & 76 & 53 & 13.2 & 11.6 & 13.2 & $33 \cdot 3$ & 24 & 1.2 & 3.1 \\
\hline $\mathrm{KN}$ & 386 & 204 & 181 & 17.4 & 15.8 & 6.2 & 32.4 & 20.5 & 6 & 1.8 \\
\hline NW & 151 & 78 & 73 & 9.9 & 11.9 & 6 & 29.1 & 19.2 & 15.2 & 8.6 \\
\hline Gau & 139 & 83 & 56 & 20.9 & 20.1 & 7.2 & 29.5 & 21.6 & 0.7 & $\mathrm{O}$ \\
\hline $\mathrm{Mpu}$ & 164 & 87 & 77 & 18.9 & 20.1 & 4.9 & 31.7 & 19.5 & 3.7 & 0 \\
\hline Lim & 140 & 72 & 68 & 8.6 & $5 \cdot 7$ & 5 & 22.1 & 27.1 & 25.7 & $5 \cdot 7$ \\
\hline Total & 1742 & 961 & 780 & 14.7 & 13 & 6.7 & 32 & $23 \cdot 3$ & 7.8 & 3.7 \\
\hline
\end{tabular}

\section{Limitation}

The analysis of the impact of illness/injuries on disabilities by type of illness/injuries does not lead to good results because of the problem of small numbers. These important differences bias the results. This is why this case has not been taken into account.

\section{Analysis}

Table 1 gives information about people living with disabilities by provincial distribution of types of disabilities. The different types of disabilities are very important to determine the impact of disabilities in the potential of the population to participate in economic activities. The results show that the most frequent disabilities in the population aged 15-49 years are physical (32\%), intellectual (23.3\%) and sight (14.7\%). Emotional (7.8\%) and communicating (6.7\%) disabilities are less common among the population living with disabilities. The provinces of Western Cape and Limpopo present some peculiarities in terms of their level of physical disabilities for people living with disabilities. The Western Cape Province is highly affected (40\%) by physical disabilities while Limpopo has a low (22.1\%) level of physical disabilities compared to the mean of the entire country, estimated at 32\%. The provinces of Eastern Cape and Limpopo with respectively 27.5\% and $27.1 \%$ have the highest level of intellectual disabilities in the country. Conversely, the provinces of the North West (19.2\%), Mpumalanga (19.5\%) and Western Cape (18.3\%) have the lowest percentages of people living with intellectual disabilities. Sight impairment in Gauteng and Northern Cape is $20.9 \%$ and $20.6 \%$ respectively.

The majority of people living with disabilities have their mother still alive (64.4\%) and their father not (62.1\% don't have their father alive). These results show that an important part of people aged 15-49 years and living with disabilities do not benefit from their parents' support. People living with disabilities are in the majority single and literate 
(68.4\% and $68.7 \%$ respectively; table not provided). To answer the question of possible relationships between illness/injuries and disabilities, the two variables have been crossed with use of the Chi-square test. The crossing of information on illness/injuries and disabilities highlights the presence of several people living in a healthy (no illness or injuries) condition with their disabilities. However, most people living without disabilities were healthier (90\%) than those with disabilities (68.3\%). At the same time, only 10\% of people without any disabilities suffer from illness (table not provided). To understand more about the relationship between disabilities and illness and the direction of this relation, multivariate analyses have been performed.

The context of South Africa is marked by a population principally young with a decrease in the number of people with an increase in age. That is the opposite situation for the population living with disabilities and those who suffer from illness/injuries. That means that people living with disabilities have more chance than others of suffering from illness/injuries because of a lack of appropriate working or living environments or because of the intrinsic influence of disabilities on health. A remarkable point coming from these findings is the constant and true increasing number of females with age among the populations suffering from illness/injuries and those living with disabilities. Indeed, the male population with disabilities or illness/injuries has almost unchanged number over the ages. This raises two questions. Why do disabilities and illness/injuries grow as women get older? Do the successive pregnancies or childbirths contribute to that, or is it only the effects of old age? In fact, the main source of illness/injuries or disabilities in South Africa is not at birth or during childhood. The number of people with illness/injuries or disabilities grew with age; that means illnesses/injuries or disabilities are appearing with age. That is probably due to new cases of disabilities or illness/injuries. But, it could also be due to international migration (return migration at old age as well) of people suffering from illness/injuries or living with disabilities, even if this hypothesis is not strong in our context.

Four variables - sex, father alive, mother alive and disabilities - show a statistical significant effect on illnesses or diseases. The findings show that the risk of suffering illnesses or injuries increases with age $(p<0.01)$. People aged 20-24 are 1.2 times more likely to acquire illness/ injuries than those aged 15-19 (age-wise distribution not presented here). This probability rose from 1.2 to 2.7 at $45^{-49}$ years (table not presented). Males are $18 \%$ less likely than females to suffer illness/injuries. People whose fathers are alive are $20 \%$ less at risk of suffering from illness/ injuries than those with their father not alive. People whose mothers are alive are $12.3 \%$ less likely to suffer illness/injuries than the others. The model also shows that the incidence of illness/injuries directly or indirectly correlates with the likelihood of disability. People with any disability have 4.01 times more risk of suffering illness/injuries than others. These findings clearly show that disabled people are more exposed to suffering illness/injuries because of the intrinsic effect of their disability situation but also the absence of support from family members or other social aspects that are gender related. 
The analysis (Tables 2 and 3) consisted of examining the mutual influence between illness/ injuries and disabilities with weighted measure. In model 1 we tried to understand the impact of disabilities on illness/injuries. Few background variables were included in the model. The outcomes of model 1 proved the clear impact of disabilities on illness/injuries. Without taking into account other variables, the result of the regression logistic shows with $99 \%$ precision that people living with disabilities are four times more likely than those without disabilities to be affected by illness/injuries. The addition of more variables (in Table 2) to control the previous result leads to the same conclusion that disabilities significantly $(p<0.01)$ influence illness/injuries. Indeed, after control, people living with disabilities have more risk than others of suffering from illness/injuries. The inclusion of socio-economic factors in the model reduces the probabilities of people who are living with disabilities to suffer from illness/injuries from 4.02 to 3.5 (model not presented). That means the influence of disabilities on illness/injuries is also due to factors such as age, sex, father survival, ability to write and marital status.

Table 2. Logistics regression those who suffered illness/injuries aged 15-49 with background variables in

South Africa (GHS, 2006) (weighted).

Model 1: Dependent variable is suffered illness

\begin{tabular}{|c|c|c|c|c|c|}
\hline \multirow[t]{2}{*}{ Variables } & \multirow[t]{2}{*}{ B } & \multirow[t]{2}{*}{ SE } & \multirow[t]{2}{*}{$\operatorname{Exp}(B)$} & \multicolumn{2}{|c|}{$\begin{array}{l}95 \% \text { confidence } \\
\text { interval }\end{array}$} \\
\hline & & & & Lower & Upper \\
\hline \multicolumn{6}{|l|}{ Sex } \\
\hline Female@ & -0.195 & 0.001 & $0.822 * * *$ & 0.820 & 0.825 \\
\hline \multicolumn{6}{|l|}{ Male } \\
\hline Father alive & -0.213 & 0.001 & $0.808 * * *$ & 0.806 & 0.810 \\
\hline \multicolumn{6}{|l|}{ No@ } \\
\hline \multicolumn{6}{|l|}{ Yes } \\
\hline Mother alive & -0.132 & 0.001 & $0.877^{* * *}$ & 0.874 & 0.879 \\
\hline \multicolumn{6}{|l|}{ No @ } \\
\hline \multicolumn{6}{|l|}{ Yes } \\
\hline Disabilities & 1.390 & 0.003 & $4.016 * * *$ & 3.995 & 4.037 \\
\hline \multicolumn{6}{|l|}{ No@ } \\
\hline \multicolumn{6}{|l|}{ Yes } \\
\hline Constant & -1.844 & 0.001 & $0.158^{* * *}$ & & \\
\hline -2 Log likelihood & 172646674 & & & & \\
\hline Cox \& Snell R Square & 0.012 & & & & \\
\hline Chi-square & 4496.805 & & & & \\
\hline Weighted observation & 25165105 & & & & \\
\hline
\end{tabular}

Source: General Health Survey (2006)

Notes: ${ }^{* *}=P<0.001 ;^{* *}=P<0.01 ;^{*}=P<0.05\left({ }^{* * *},{ }^{* *},{ }^{*}\right.$ indicate level of significance at specified level); $@=$ reference tegory.

The findings confirm that all the different types of disabilities significantly $(p<0.01)$ influence illness/injuries except communicating disabilities (model not presented). The influence of communicating disabilities on illness/injuries is not statistically significant at 10\%. Moreover, the other disabilities positively influence illness/injuries. However, people living with emotional and physical disabilities are the most vulnerable to illness/injuries with respectively 4.4 and 3.5 more chance of suffering from illness/injuries than others. 
We also found that the addition of socio-economic variables affects the risk of illness/injuries among people living with disabilities whatever the types of disability.

Table 3 reveals very interesting results concerning the influences of illnesses/injuries on disabilities. Old people are more likely than those aged less than 20 years $(p<0.01)$ to be affected by disability. Findings show that people aged above 20 years are 1.2 times more at risk of disability than those aged 15-19 years. People who don't have their father alive are $33 \%$ less likely than others to suffer from disabilities (Table 3 ).

The influence of illness/injuries on disabilities is strongly significant with $99 \%$ of precision and socio-economic factors also having an important role in this influence. Concerning gender, females are 1.5 times more likely than males to suffer disabilities. When the father is alive, the risk of suffering disabilities is $33 \%$ less than when he is alive. People who do not have the ability to read and write are more at risk of disabilities than others (odds ratio is 1.4). From these findings, we understand that people suffering from illness/injuries are more likely to suffer from disabilities and they are more exposed when they are male, getting old or orphaned and illiterate. In other words, illnesses/injuries, family support (father, mother and spouse alive) and education (ability to read and write) and old age are the important causes of disabilities among people of South Africa.

Table 3. Multivariate analysis in a form of logistic regression step method between disabilities by background variables in South Africa 2006.

Weighted model: dependent variable: disabilities status

\begin{tabular}{|c|c|c|c|}
\hline \multirow[t]{2}{*}{ Variables } & \multicolumn{3}{|c|}{$95 \%$ confidence interval } \\
\hline & $\operatorname{Exp}(B)$ & Lower & Upper \\
\hline \multicolumn{4}{|l|}{ Sex } \\
\hline Male@ & $1.48 * * *$ & 1.47 & 1.48 \\
\hline \multicolumn{4}{|l|}{ Female } \\
\hline \multicolumn{4}{|l|}{ Age } \\
\hline 15-19@ & $1.21 * * *$ & 1.20 & 1.22 \\
\hline \multicolumn{4}{|c|}{ Others } \\
\hline \multicolumn{4}{|c|}{ Spouse alive } \\
\hline No@ & $0.61 * * *$ & .61 & 0.61 \\
\hline \multicolumn{4}{|l|}{ Yes } \\
\hline \multicolumn{4}{|c|}{ Mother alive } \\
\hline No@ & $0.60 * * *$ & 0.59 & 0.60 \\
\hline \multicolumn{4}{|l|}{ Yes } \\
\hline \multicolumn{4}{|c|}{ Father alive } \\
\hline No@ & $0.67 * * *$ & 0.64 & 0.71 \\
\hline \multicolumn{4}{|l|}{ Yes } \\
\hline \multicolumn{4}{|c|}{ Ability to read and write } \\
\hline Yes@ & $1.4^{* * *}$ & 1.39 & 1.41 \\
\hline \multicolumn{4}{|l|}{ No } \\
\hline \multicolumn{4}{|l|}{ Diarrhea } \\
\hline No@ & $1.37 * * *$ & 1.33 & 1.41 \\
\hline \multicolumn{4}{|c|}{ Yes } \\
\hline \multicolumn{4}{|c|}{ TB \& severe cough } \\
\hline No@ & $3.15^{* * *}$ & 3.09 & 3.20 \\
\hline Yes & & & \\
\hline
\end{tabular}




\begin{tabular}{|c|c|c|c|}
\hline \multicolumn{4}{|l|}{ Blood pressure } \\
\hline $\mathrm{No}^{@}$ & $2.91 * * *$ & 2.85 & 2.96 \\
\hline \multicolumn{4}{|l|}{ Yes } \\
\hline \multicolumn{4}{|l|}{ HIV/AIDS } \\
\hline No@ & $7.78 * * *$ & 7.60 & 7.97 \\
\hline \multicolumn{4}{|l|}{ Yes } \\
\hline Constant & $0.05^{* * *}$ & & \\
\hline-2 Log likelihood & 6179356.5 & & \\
\hline$x^{2}$ & 948.876 & & \\
\hline Cox \& Snell R Square & 0.005 & & \\
\hline No. of observation & 55384 & & \\
\hline
\end{tabular}

Notes: ${ }^{* * *}=P<0.001 ;{ }^{* *}=P<0.01 ;^{*}=P<0.05\left(* * *,{ }^{* *},{ }^{*}\right.$ indicate level of significance at specified level; @ = reference egory).

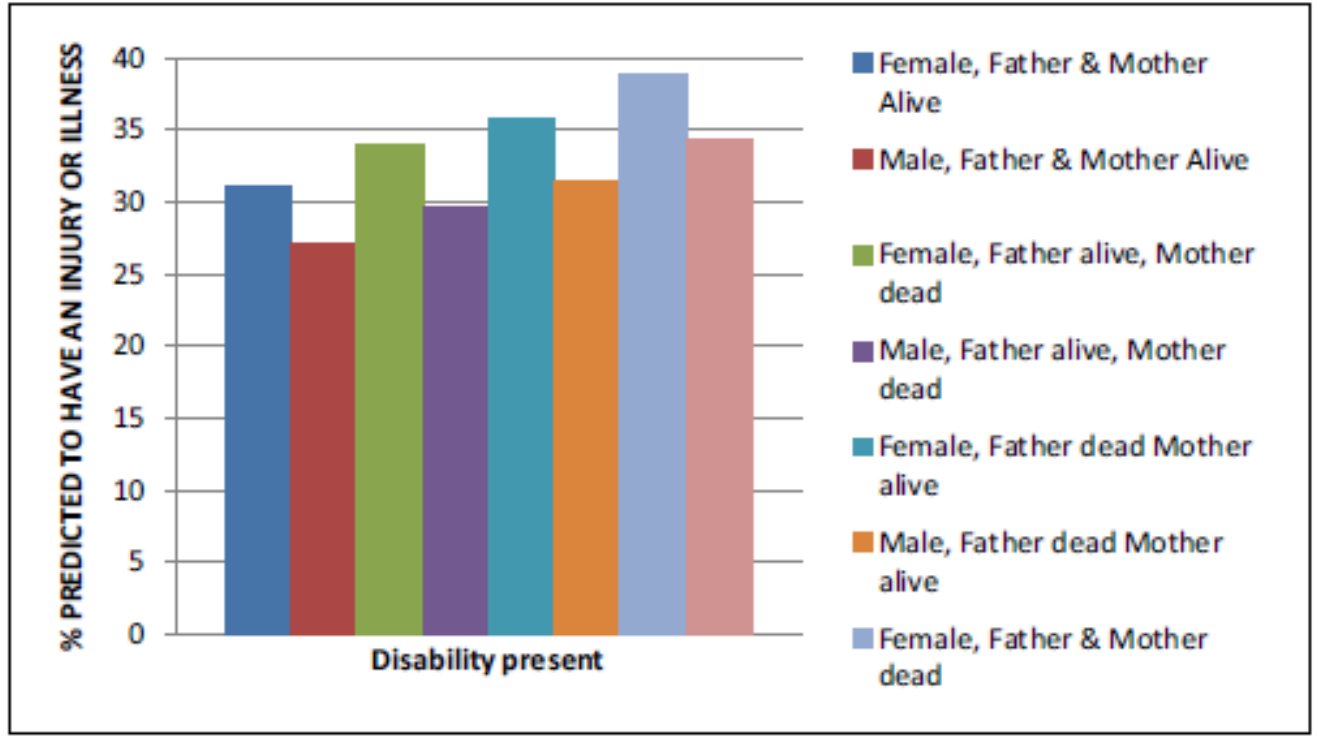

Figure 1. Logit link predictions when disability is present.

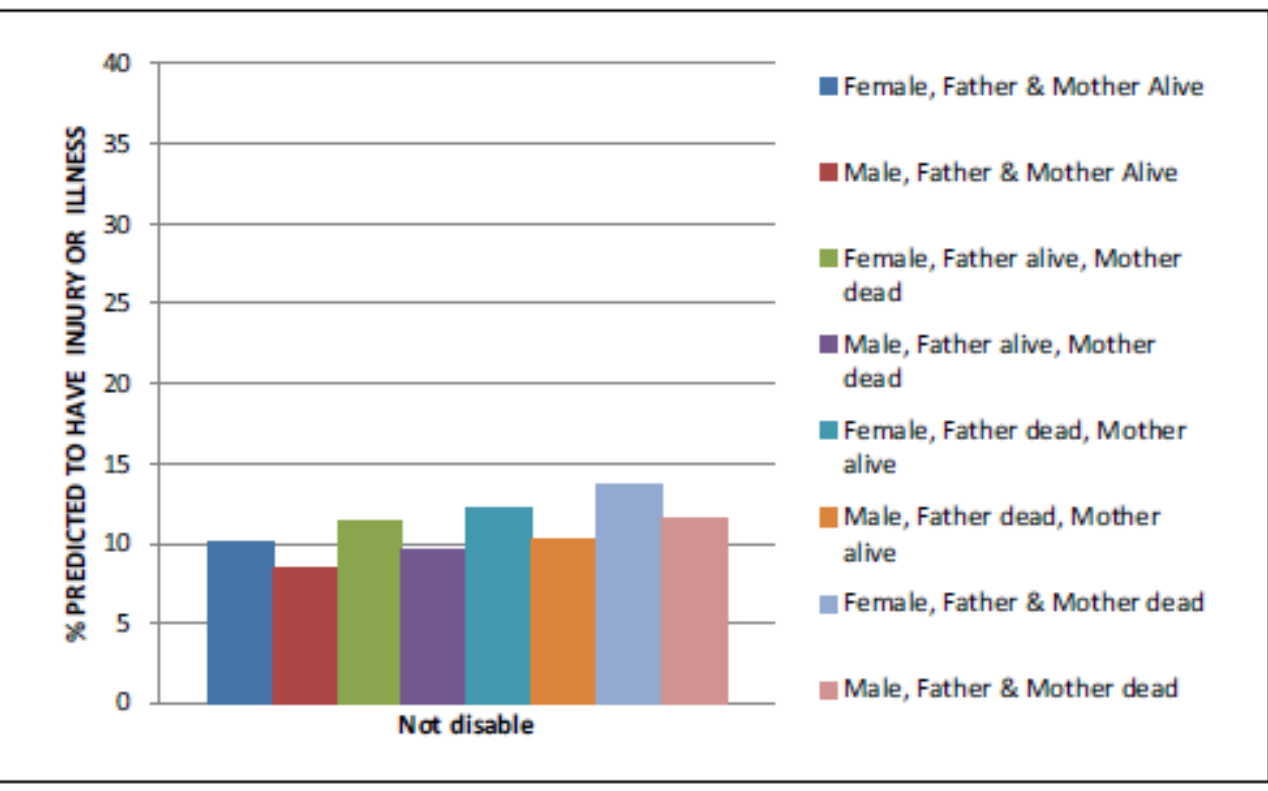

Figure 2. Logit link predictions when disability is not present. 
Regarding the importance of family support (father alive, mother alive, spouse alive) in the likelihood of illnesses/injuries and disabilities, an advance analysis has been undertaken to understand the relationship between family support of disabled and nondisabled and illnesses/injuries (Figures 1 and 2). Figure 1 and 2 show the logit link predictions of illnesses/injuries when disability is present and not present by gender (male, female) and family support (father and mother alive). These graphs show that illnesses/injuries are highly predicted by the survival status of the mother or father and the gender. People living with disabilities are more likely (higher prediction level) than the nondisabled to suffer illnesses/injuries. Disabled, orphaned females are the most exposed to illnesses/injuries. In the domain of disabilities, these findings appear to be very important and accountable among the original findings of this study.

\section{Discussion}

Disabilities influence illness/injuries directly and indirectly via variables such as age, sex, family support and literacy. We showed that the lack of support and education, age and sex are important parts of the risk of exposure to illnesses/injuries. Variables considered as reflecting socio-economic support are the father's and mother's survival. In general, the vulnerability of people living with disabilities regarding their exposure to illnesses/injuries also depends on what they are suffering from. People living with disabilities' need for support and their risk of suffering illness/injuries differ according to the type of disabilities. This analysis shows the peculiarities of some kinds of disabilities such as communicating and intellectual disabilities concerning their impact on illness/ injuries. Only people living with intellectual disabilities have the same chance of suffering illness/ injuries whatever their socio-economic environments. Besides communicating and intellectual disabilities, people living with other disabilities have more risk of suffering illness/injuries when they get old, are females, are not single and their father is not alive. People with physical and sight disabilities are more vulnerable to their socio-economic environment in terms of risk of illness/ injuries. The impact of disabilities on illnesses/injuries did not mean that the reversed influence of illness/injuries on disabilities is significant. However, people who suffer from illness/injuries have a higher chance of being affected by disabilities. When including selected background variables in the model, people suffering illness/injuries are more exposed to being affected by disabilities than those who are healthy. The analysis of

disability risk factors shows that disability is the consequence of illnesses/injuries. But females are more exposed to disabilities as well as those who do not have support from mothers, fathers or spouses.

\section{Conclusion}

The increasing number of people suffering from disabilities in South Africa illustrates the important need in this domain because these people have problems different from others. The number of people living with disabilities and suffering from illness is quite high in all the provinces of South Africa. Most people in the age group 15-49 years suffer from illness due to various reasons. Prejudices and discrimination due principally to the lack of knowledge about disabilities are problematic worldwide. Generally, people living with disabilities are seen as people affected by illness/ injuries. But the relationship between 
disabilities and illness is not always scientifically proven. In addition, the sense of the relationship and risk factors has not yet been sufficiently explored by scientists. In view of contributing to fill this gap, this article was initiated to examine the relation between disabilities and illness with an emphasis on the sense and the importance of the influence they have on each other. The purpose of this work was to contribute to the understanding of illness/ injuries and disabilities in South Africa in order to change the way people living with disabilities are seen in society. The findings show that disabilities acquired at adult ages are as many as those acquired at birth. In contrary to common knowledge, this finding shows that disabilities not only start at birth and therefore it is possible to considerably reduce disabilities.

The findings of this article confirm the high level of association between disabilities and illness/ injuries. The influence of disabilities on illness/injuries has been established as significant, and the reversed influence of illness/injuries on disabilities is also significant. The key finding of this study is the mutual influence between illness/injuries and disabilities through a direct impact but also indirect via background factors such as age, sex, father alive, marital status and ability to read. In contrary to what people usually think, the relationship between disabilities and illness is not only due to the disability: socio-demographic variables play an important role on this relationship. According to the type of disability, this paper shows the possibilities of reducing illnesses among people living with disabilities and reducing disabilities among the total population by taking some socio-economic measures such as bringing support to orphans and giving more attention to females in programs against disabilities.

\section{Principal Recommendations}

The findings of this study suggest accelerating the fight against disabling diseases to reduce disabilities among the population. An emphasis has to be made on those living with intellectual disabilities. Proper medical preventive services are not sufficiently available although their use is an important way to reduce the underlying causes of illness, injury and disabilities. Places of living, working and playing should be improved for people living with disabilities by taking into consideration their specific needs. The implementation of this recommendation will considerably reduce illness/injuries among disabilities, in particular those who are living with physical or sight disabilities. Lack of adequate transport is also a major problem, especially in rural areas. Employment for people living with disabilities should be promoted to allow them to reach empowerment in adulthood and take care of their health needs. Poor people are likely to experience delays in receiving appropriate treatment or to not get access to health services when needed. Lack of employment makes people living with disabilities usually dependent on support from parents even at working ages. Education of people living with disabilities should be promoted by reinforcing the fight against discrimination and marginalization at school.

This study led to results that should be further explored in studies for better understanding disabilities and illness/injuries. In-depth research is needed on this issue regarding the consideration of more background variables including employment of people living with 
disabilities, number of years of suffering from disabilities and environment of work, playing and accommodation. These are among other factors that could allow us to better understand about the issue of illness and disabilities.

\section{Acknowledgments}

The authors would like to thank Statistics South Africa for providing data sets and offer special thanks to Prof. Richard Madsen, University of Missouri, United States, for his valuable suggestions and critical comments.

\section{Funding}

University of the Western Cape Research Fund.

\section{References}

Ahlburg D, Ali M, Breeze E, Grundy E and Sloggett A (1999) Disability in Great Britain: Results from the 1996/97 Disability Survey. Research report no. 1994. London: Department of Social Security.

Banister J and Zhang X (2005) China, economic development and mortality decline. World Development 33: 21-41.

British Council of Organizations of Disabled People (1987) Summary on the Report of the Audit Commission. London: British Council of Organizations of Disabled People.

Cambois E, Jacobzone S and Ronine JM (1999) Is the Health of Older Persons in OECD Countries Improving Fast Enough to Compensate for Population Ageing? Paris: OECD.

Desai AN (1990) Helping the Handicapped: Problems and Prospects. New Delhi: Allied Publication House.

General Household Survey (2006) Statistics South Africa, National Library of South Africa, Pretoria Division, Stats SA. Available at: www.statssa.gov.za.

Kapteyan A (2004) Measuring Disability. Population Association of America. Annual Meeting Program, Session, 1-3 April: 142-144

Mehta DS (1983) Handbook of Disabled in India. Ahmadabad: Allied Publishers Pvt. Ltd.

Murray CJL (2007) Can we achieve millennium development goal 4? New analysis of country trends and forecasts of under-5 mortality to 2015. Lancet 370: 1040-1054.

Pathmanathan Dhairiam S (1990) Malaysia: Moving from infectious to chronic diseases. In: Tarimo E (ed.) Achieving Health for All by the Year 20oo: Midway Reports of Country Experiences. Geneva: World Health Organization, 19.

Quinn G and Degener T (2003) A Study on the Current Use and Future Potential of the UN Human Rights Instruments in the Context of Disability. Geneva: UN Human Rights Commission.

Sen A and Wolfensohn J (2003) Helping disabled people to come out of the shadows. Global Viewpoint. Available at: http://www.worldbank.org.cn/English/content/382b63052692 html (accessed 26 January 2005). 
World Health Organization (1980) International Classification of Impairments, Disabilities and Handicaps: A Manual of Classification Relating to the Consequences of Diseases. Geneva: WHO.

World Health Organization (1985) Targets for Health for All. Copenhagen: WHO Regional Office for Europe.

World Health Organization (2001) International Classification of Functioning, Disability and Health. Short version. Geneva: WHO.

World Health Report (2002) Reducing Risks, Promoting Health Life. Geneva: WHO.

\section{Author biographies}

A Sathiya Susuman has an MA, MPhil in Population Studies and a PhD in Demography. He has specialized in the social science research area of demographic analysis and reproductive health for 14 years. His specific research area is fertility, mortality and public health. He has published several articles in reputed journals. He currently works as Senior Lecturer in Demography at the Department of Statistics and Population Studies, University of the Western Cape, South Africa.

Renette Blignaut has a PhD in Statistics and is Associate Professor and Deputy Chairperson at the Department of Statistics and Population Studies, University of the Western Cape, South Africa. Her special area of research is biostatistics, science education and data mining.

Siaka Lougue successfully completed and recently submitted a PhD thesis at the Department of Statistics and Population Studies, University of the Western Cape, South Africa. 